\title{
Dueling Paradigms: Politics and Pedagogy in a Postmodern Discipline
}

\author{
Paul Witkowsky \\ Radford University
}

In the Winter 1999 issue of the South Atlantic Review, at the end of a review of yet another polemic in the struggle for the soul of literary studies, the reviewer asked plaintively, "Is there any middle ground in the Culture Wars?" (Schilb 170). I would like to suggest at least the possibility of such a middle ground, both because such a middle ground makes sense on its own terms and because, in the absence of some sort of unifying compromise, those of us in departments of English (or Spanish, or any other departments involved in literary studies) risk the loss of any common institutional rationale for what it is that we do. I come not to bury postmodernism or to praise it; it would be premature to do the former, and there is no shortage of candidates to do the latter. My intention is more modest, and arguably more practical: to explore some of the problems raised by postmodern approaches to the teaching of English, and to suggest a way of integrating such approaches into a unified field theory for English studies. As Edward Said recently observed in his President's Column in the MLA Newsletter, "When reputable, distinguished departments of literature can no longer function without terrible, paralyzing disagreements on the smallest as well as the largest issues, something is quite wrong" (3). There has to be a better way.

Let me start by situating myself. For most of the last twenty-one years-that is, except for a three-year interlude at the University of Seville-I have taught in a department in the United States that offers courses in a number of different areas. Like many other English departments, we have courses in expository writing, literature, literary criticism and critical theory, creative writing, business and technical writing, language and linguistics, and the teaching of English - a situation that in itself, independent of any culture wars, lends credence to Peter Elbow's observation that English is "a profession that cannot define what it is" (v). Most of us teach in at least two of those areas; mine are literature and language and linguistics.

My own degree is in American literature. I like to think that my dissertation-on the cultural significance of the frontier as it is represented in nineteenth-century fiction-was in some ways an exercise in intertextuality and in proto-New Historicism, but the truth of the matter is that I received my degree before the mythical era of postmodernist hegemony. As a student of postmodernism I am thus an autodidact, and very much aware of the gaps in my own knowledge. Especially because of my interest in linguistics and in the history of the English language, and because of my belief that students of literature should also be exposed to the study of language, I have even been accused by one of my colleagues of wanting to turn our disciplinary clock back to the nineteenth century. In fact, however, it is 
in my linguistics classes that I have found the clearest evidence of the inadequacy of a purely postmodernist approach, and of the need to find a more satisfactory unified-field theory for English studies. Two exchanges with students in two different classes have helped to convince me of that need.

The first exchange occurred two years ago in my graduate linguistics course. In the middle of a discussion of phrase structure rules, one of my students suddenly interrupted to ask an apparently irrelevant question: "In this class we're taught that language operates according to rules and that those rules exist in some objective sense; then, in our next class, we're taught that objective reality is a fiction and that everything is a social construct. What are we supposed to do? How are we supposed to reconcile those two positions? As students, how do we make sense of this situation?" In a larger sense, of course, the question was not irrelevant at all. The student asked it not out of hostility but out of genuine puzzlement; if it was transgressive, it seemed to me that the assumptions that were being violated, or at least interrogated, were those of the graduate curriculum in general rather than of my course in particular. We were not able to answer her question in half an hour borrowed from a discussion of generative syntax, but at least we were able to address the philosophical problem underlying her question, and to acknowledge the practical consequences of such a problem in a graduate program like ours.

The second exchange occurred just last spring in my undergraduate linguistics course; this time the student was, in fact, hostile. The problem lay in my use of Steven Pinker's The Language Instinct as a required text, along with a more conventional introduction to linguistic study. (Pinker's book is a superb introduction to current linguistic thought for a general audience; essentially - and with an interestingly Darwinist bias - he uses the insights of cognitive science to explain the results of the Chomskyan revolution. I had also assigned it because Pinker himself, who is the director of the Center for Cognitive Neuroscience at MIT, was coming to Radford to lecture in April, and would visit our class to answer students' questions.) In one of her early journal entries, the student complained that she was getting tired of Pinker: "Maybe I am beginning to catch a little spring fever, but I think it would be nice to have other opinions on linguistics other than Pinker's views and what he chooses to include in his text. I feel like this is the same thing that literary criticism would be if we read only one theorist and believed everything he said, and paid absolutely no attention to what anybody else had to say."

This seemed like an easy complaint to answer, and in fact a useful issue to raise with the class as a whole, especially in view of my earlier experience in my graduate class. I explained the difference between literary theory and linguistic theory, and pointed out that Pinker's theories — unlike, for example, those of Derrida or Foucault or Irigaray or Greenblatt - are mostly in the mainstream of his discipline, commonly accepted and in fact the basis of nearly all general linguistics texts, including our own. But that was apparently not enough. Two months later, in an essay summing up her experience in the class, the same student wrote,

At this point in time, I also disagree with the course title. A more appropriate title would be "Pinker 10i." I realize that you have said Pinker's linguistic views are mainstream, and 
probably the easiest to understand. However, during my three years at Radford University, one of the most important things I have learned to do is cover all my options. If I wrote a scholarly article on Shakespeare and consulted only one work written by an outside source, I doubt if anyone would consider my work scholarly-including myself.

With only a few exceptions, we have not heard what other linguists have to say about the ideas addressed by Pinker. How do I know who else is mainstream, or what makes what Pinker says mainstream? I think this is a lot like what it would be like to walk into a history class and hear a lecture on the topic of slavery, but only hear the slave owner's opinions and thoughts on the subject. I would want to hear what the slaves have to say, then come to my own conclusion. I think that would make a lot more sense, and make my knowledge more well-rounded.

I was annoyed at the student's insistence on an irrelevant objection that I thought I had explained away; I commented in my response to her essay that it seemed to me that she had devoted an inordinate amount of energy to missing the point. I do not think, however, that her hostility was a random occurrence, nor that it was simply the result of a dislike for me or for the material. (In fact, she had devoted sufficient energy to learning the material to earn an $\mathrm{A}$ in the class.) At the risk of being paranoid, I believe that her insistence on the insufficiency of a single "theory" in linguistics was the consequence of her indoctrination into a Procrustean postmodernism, and that that indoctrination (in courses taught by professors committed to "theory" in literary studies) is evidence of the philosophical and practical problem facing English studies as a discipline today. Unless we can facilitate some sort of stable coexistence between postmodernist and other approaches to English studies, and even among the various postmodernisms, we run the risk of fragmentation and ultimate irrelevance, or at least of making our students choose, as a condition for entering the discipline, between cognitive dissonance and Orwellian doublethink: the power "to know and not to know ... to hold simultaneously two opinions which [cancel] out, knowing them to be contradictory and believing in both of them" (32).

In fact, my undergraduate student's dutifully postmodernist response-that is, her absolute insistence on epistemic relativism-is a good place to begin to unpack the disciplinary dilemma that I think we face, a dilemma embodied in the problem of "theory." Back in the days when we taught a unit on formal logic as part of a first-year writing course, one of the fallacies that my students most appreciated was equivocation: the exploitation of lexical or structural ambiguity in order to mislead or deceive, as in the elision of the difference between "angry" and "insane" in American usage in the sentence, "He is mad at me, and anyone who is mad belongs in a madhouse." What my linguistics student was guilty of was equivocation-unintentional, to be sure, but nevertheless emblematic of the way in which an essential difference between empirical and non-empirical epistemologies has been ignored or denied in the rush to postmodernism.

Half a century ago René Wellek and Austin Warren defined the purpose of their Theory of Literature as "to formulate the assumptions on which literary study is conducted (to do which one must go beyond 'facts')," but at the same time they acknowledged that the relationship between their theory and their facts was not inductive in any scientific sense: "the literary examples cited are always examples, not "proof"' (7). Their theory was not falsifiable; there was nothing about it that could be proved wrong. Nor did it have any predictive 
value; its only usefulness was in relation to "facts" already at hand. It was not like quantum theory, or the theory of relativity; it was "theory" in an entirely different sense, and I doubt that anyone reading Wellek and Warren's book would have had any doubt about the distinction.

What has happened since Wellek and Warren, of course-especially in the last twenty years-is a much more pervasive "theorization" of literary studies, especially of the relationship between literary studies and other disciplines. On the whole, this has been a salutary phenomenon in that it has forced us to recognize that every critical practice is founded on an ideology of one sort or another, no matter how covert or unacknowledged. (In my own experience, in fact, much of the resistance to "theory" is a more general refusal to concede that literature and literary criticism are ideologically implicated activities. This can be seen in the attitude of the die-hard formalists in my own or any other department of English.) But it is also true that much of this turn to theory has been more specifically in the direction of what has come to be called postmodernism: epistemic relativism, social constructivism, a commitment to the idea of the fundamental ambiguity of language and of the ultimate indeterminacy of meaning. Terry Eagleton and Christopher Norris argue that much of this phenomenon is a reaction to the failure and marginalization of left-wing politics; in Eagleton's words, "in a period when no very far-reaching political action seems really feasible, when so-called micropolitics seems the order of the day, it is relieving to convert this necessity into a virtue-to persuade oneself that one's political limits have, as it were, a solid ontological grounding" (9). But if political action has been sublimated as dialectic, the struggle for power has not been abandoned; it has simply been displaced from the macropolitical level of national and international affairs to the micropolitical level of disciplinary and curricular politics, and it is at this level that the problem of "theory" acquires special significance.

Even if Eagleton and Norris are correct in their analysis, and the rise of postmodernism as antipolitics can be credited to Thatcher, Reagan, and other scourges of the political left, it seems to me that narrower institutional forces have also played a role in the theorization of English studies. As the status of the humanities in general has been weakened by an increased emphasis on professional and vocational education at the undergraduate level, and as the social sciences have become increasingly quantitative in an attempt to duplicate the prestige of the hard sciences, there has been a corresponding pressure on humanistic disciplines such as English studies to justify themselves in similarly "scientific" terms. In 1983, at the European Fulbright Conference in Berlin-when my self-education in postmodernism had not yet begun in earnest-a fellow lecturer asked me what my theoretical approach was, and when I answered that my approach was more eclectic than narrowly theoretical, she asked, "How can you be sure that what you do in one case is consistent with what you do in another?" (She may even have asked me whether the results of my researches were reproducible; postmodernist or not, at a distance of sixteen years one's memory is indeterminate at best.) Theory is explicitly systematic, intellectually rigorous; whatever other function it may fulfill, and however much it has amused, bemused, and alienated cultural conservatives and the public at large-as witness the annual Christmastime press ritual of poking fun at the titles of sessions and papers at the convention of the Modern 
Language Association-theory has allowed the discipline of English studies to claim a new measure of intellectual and institutional respectability at a time when its traditional place in the curriculum is no longer so universally self-evident.

But if postmodernists are more "scientific" than, say, New Critics-that is, less hieratic in their approach, more committed to exploring and explaining the theoretical foundations of their critical methodologies, more candid in acknowledging the ways in which literature and literary criticism are implicated in broader cultural discourses-they are still not scientists, and their theories are no closer to being scientific than were Wellek and Warren's. The position of many postmodernists, of course, is that scientific theories aren't "scientific" either; drawing on Thomas Kuhn's The Structure of Scientific Revolutions and on more recent critical histories of science, they argue that science and scientific investigations, including the "objective" results of those investigation, are implicated in the same cultural discourses. The evolving discipline of science studies, for example, is based on the use of postmodern theory to interrogate the programs and practices of the physical and biological sciences.

Science studies, however, is hardly an uncontested field. As far back as 1995, for example, the New York Academy of Sciences organized a conference under the rubric "The Flight from Science and Reason" (the proceedings of which were later published under the same title), and the following year saw the controversy over Alan Sokal's now famous (or, depending on one's perspective, notorious) article, "Transgressing the Boundaries: Toward a Transformative Hermeneutics of Quantum Gravity." Sokal, a professor of physics at New York University, was so disturbed by what he saw as the ignorance and tendentiousness of postmodernist critiques of science that he wrote his own pseudo-critique-a parody based on a pastiche of the ideas of a number of postmodern theorists-and successfully submitted it to the journal Social Text.

Since then, in collaboration with Jean Bricmont, a physicist at the University of Louvain, Sokal has developed his position more explicitly in Fashionable Nonsense: Postmodern Intellectuals' Abuse of Science. They insist that their quarrel is not with postmodernism in general, which they admit they are not qualified to judge, but with the way in which writers like Lacan, Kristeva, Irigaray, and Baudrillard have justified their theories by appealing to mathematical and scientific models that were either irrelevant or poorly understood or, in some cases, completely meaningless. The less sensational title of the original French edition, Impostures intellectuelles (reflected in the title of the Spanish edition, Imposturas intelectuales) seems to me more faithful to their argument: not that all postmodernism is nonsense (fashionable or otherwise), but that postmodernist attempts to claim a scientific basis for their own conclusions-that is, to equate literary and cultural theory with scientific theory-are in fact an imposture.

In other words, if Sokal and Bricmont are right, my student's unwitting equivocation on the word "theory" was not accidental, or the evidence of any lack of intelligence or understanding on her part, but arguably the inevitable result of her education in the postmodernist worldview. And if we do not place that worldview in a larger context, if we do not provide our students with a means of understanding the relationship between postmodern theories 
and other aspects and constituents of English studies, we run the risk not only of doing our students a disservice, but of marginalizing ourselves and our discipline as a whole. The postmodernist, multiculturalist takeover of departments of English-at least in the United States-may be a myth created by cultural conservatives for political purposes, but the philosophical and pedagogical concerns underlying their fears should not necessarily be dismissed out of hand. As Mary Poovey observes in a recent review of a collective jeremiad, What Happened to the Humanities?

As an occasional ... target of laments like these, I have generally tended to dismiss such arguments as the death throes of soon-to-be-extinct disciplinary conservatives. Like many other members of my academic generation, however, I have become increasingly aware that, even if the remedies these writers suggest are unpalatable, their complaints do have some validity. ... [I]t is true that literary studies has become theoretically incoherent, not just because of the influence of continental theory but for reasons internal to the way the discipline has been institutionalized in the university system. (356)

The problem of theory is one source of Poovey's unease: What effect do the multiple theorizations of our discipline have on its practice? As she indicates, however, "theory" is not the only point of contention between postmodernism and its critics, or the only potential source of discomfort to its supporters. I would like to suggest that the notion of textuality is equally problematic: What constitutes a "text"? Or, to put it another way, what is the proper object of our critical methodology? If we address those two questions, at least briefly, I think that we can begin to address the need for a unified field theory in literary studies in general, and in English studies in particular.

As far as theory is concerned, as Richard Nixon used to say, let me make one thing perfectly clear. I am not "against" theory-especially since there is no such thing as "theory," anyway. Theories, yes; "theory," no. One of the excesses of postmodernism, at least in its grass-roots manifestations in departments like mine, has been the reification of "theory" as the solution to nearly any problem in literary or cultural studies. A few years ago, for example, I was on the committee for a master's thesis on Michael Arlen's The Green Hat, a long-forgotten "lost generation" novel that was a massive best-seller in both Great Britain and the United States in 1924; when I criticized an early draft for attempting to account for the novel's popularity without reference to the specific historical and cultural circumstances of postwar England, another member of the committee dismissed my objection on the grounds that "Theory can explain it." To this day I am not sure exactly what he meant by "theory," or how "theory" was supposed to operate in the absence of historical "facts"; and there still seems to be something fundamentally lacking in an approach that so cavalierly dismisses the distinction between "facts" and "theory."

Even if we bracket the attempt to establish an equivalence between postmodernist theory and the natural sciences-Sokal and Bricmont's particular bête noire-my experience as a teacher and as a member of an academic community suggests that the relationship between theory and practice both in criticism and in teaching is still problematic. Poovey, in fact, elaborates specifically on this issue in her review, pointing out that an inability to distinguish facts from theories, and from speculations based on those theories, is indeed a source of concern. After observing that "In the hands of its most sophisticated practitioners, 
these kinds of theory-informed approaches to the novel have yielded exciting explorations of a series of abstractions for which we otherwise lack analytical instruments," she points out that "neither disciplinary nor professional grounds yet exist that are capable of establishing the validity of nonempirical methods," and that current approaches necessarily "combine theoretically innovative claims with methods that derive from the formalism that is indebted to both aesthetics and empiricism." And she goes on to use Eve Kosofsky Sedgwick's Epistemology of the Closet as a case in point:

As provocative as [her opening sentence] is, all Sedgwick offers to support it are the kind of textual analyses that offer her own, theory-driven interpretations as evidence. Sedgwick does not explore the problematic relationships among theory, interpretation, and evidence, nor does she realize that assigning interpretations the status of evidence casts interpretations as facts-a move that renders all the truth-claims supposedly derived from such facts mere confirmations of the theoretical position from which the critic set out. Treating interpretations as facts, in other words, makes this kind of argument circular. (369)

As Poovey herself acknowledges, a hard-core postmodernist-that is, an unreconstructed social constructivist-would probably argue that there is no essential difference between a "fact" and an "interpretation." That may be so, to a postmodernist; but given the less than hegemonic status of postmodernism in literary studies, let alone in the academy or the culture as a whole, I think that we ignore the distinction at our peril. One potential consequence of epistemic relativism is exactly the kind of theoretical incoherence that Poovey warns us about—or at least the appearance of incoherence, which can be just as damaging. In a discipline in which paradigm shifts seem to occur with astonishing regularity-perhaps because philosophical epiphanies are too easily confused with paradigm shifts, especially by those having the epiphanies-we run the risk of seeming to level all distinctions among competing "theories." And, for example, unless we are willing to concede the fundamentalist argument that both evolution and creationism are "theories" and therefore equally deserving of being taught in the biology classroom, we need to acknowledge the sorts of distinctions that my undergraduate student had been trained to resist. If we continue to insist on a totalizing relativism, we will simply lose credibility with our non-postmodernist colleagues, especially those for whom, like Sokal and Bricmont, paradigm shifts are not common occurrences, facts are not contingent, and all theories are not created equal.

If the postmodern insistence on theory is problematic for departments of English and for the discipline of literary studies in general, the insistence on textuality, or textualization, is equally troublesome. The former has led to a subdisciplinary fragmentation and to the perception that the discipline formerly, if occasionally uneasily, known as English has been colonized by philosophy, history, and other disciplines in the humanities and social sciences; the latter has led to an interdisciplinary blurring of boundaries and to the perception (not always unjustified) that literary critics are poaching on other scholars' territories. A recent dictionary of critical terms suggests the nature of the problem:

In its most usual sense, text refers to any written or printed document, whether literary or not. . . . Following Barthes, the term ... has been adopted by poststructuralists to refer to any DISCOURSE that produces meaning through its infinite play of SIGNS. Some critics and 
theorists have gone as far as to refer to any system of signs as a text. (Childers and Hentzi 303)

In the old days there were literary texts and nonliterary texts. It was certainly possible to argue, especially in the area of popular culture, that the distinction was arbitrary and in fact a prime example of a cultural construct; but at least the old institutional divisions took for granted the limitations of discipline-specific methodologies. I am no more against interdisciplinarity than I am against theory; one of the most interesting projects that I have been involved in was a course on "Literature and the Arts in the Contact Zone," team-taught with professors of art and music as a pilot course for a proposed New College of Global Studies at my university. But interdisciplinarity should be in fact interdisciplinary, not a function of English professors, i.e. trained readers of texts, declaring everything to be a text and therefore a suitable object for their own disciplinary scrutiny.

One of the things that I like about working with literature is the fact that it gives me the opportunity to learn and think and talk about everything else as well. (Huckleberry Finn embodies historically situated discourses of race and gender; Theodore Dreiser's The Financier can only be understood in the context of robber-baron capitalism and social Darwinism; in teaching The Education of Henry Adams or the novels of Thomas Pynchon I turn physicist and explain the Second Law of Thermodynamics; when I talk about The Great Gatsby I have to allude at least briefly to Prohibition, Teapot Dome, and the Black Sox scandal of 1919.) But, however historicist my own critical tendencies may be, I need to be careful not to overstep the limits of my own competence. Borrowing from other disciplines is not the same as colonizing them. I need to be sure that I am not reading beyond my own training and capabilities, and that I am not simply appropriating whatever non-literary texts will best suit my purposes at the moment. For example, when my graduate students in a seminar on "Text and Context in American Fiction at the Turn of the Century" read Walter Benn Michaels's new-historicist collection of essays, The Gold Standard and the Logic of Naturalism, they were troubled by his readings of "texts" as diverse as trompe-l'oeil paintings, court decisions and law-review articles on corporate personality, Psychopathia Sexualis, Venus in Furs, and turn-of-the century treatises on photography, and wondered whether his choice of extraliterary texts was in fact determined by what he was already predisposed to find in the novels that were his chief concern. In terms of Poovey's analysis, my students-even those whose interests could be described as postmodernist-were suspicious that Michaels's intertextual readings were simply a means of allowing him to represent his interpretations as facts.

What, then, is to be done? If the postmodernist approach, however valuable its insights, is indeed incomplete-as I think it is—and if, as practiced in departments such as mine, it is insufficiently compatible with other approaches-as it certainly seems to be-then we all have a problem, individually as teachers and scholars and collectively as colleagues in a disciplinary endeavor. As Mark Turner writes in his "Pretext" to Reading Minds:

Speaking within the professional family, we might admit that although we can continue to produce ever more specialized treatments of our favorite works for an ever more specialized audience, we lack any common and commonly respected conception of the activity of 
the profession. Part of the definition of a profession is that practitioners not too far removed from each other in time must be able to recognize each other's activities. ...

We do not in the profession acknowledge a common activity that makes us one profession, and do not have one place where we touch home base and ground our work in the full human world.

In the next paragraph, however, Turner suggests the possibility of such a commonality and such a grounding: "I propose that what the profession lacks is a concept of language and literature as acts of the everyday human mind. If we had such a concept, our grounding activity would be the study of language and of literature as expressions of our conceptual apparatus" (5-6).

The subtitle of Turner's book is Studying English in an Age of Cognitive Science, and it is just such a cognitive approach that I would like to offer-along with Turner-as a common ground for English studies, a possible means to a unified field theory capable of redeeming our discipline from intellectual incoherence. Cognitive science has already shaped the ways in which we approach the study of language: generative linguistics is based on a testable theory of mind, and the insights derived from cognitive research-into language acquisition, for example-have helped us understand the ways in which we learn and produce language. But literary studies has resisted such an approach, and much postmodernist criticism is in fact based on the idea that each of us is a tabula rasa, shaped entirely by particular cultural discourses and not at all by the universal cognitive structures of our minds. And I would like to propose that, rather than representing a sterile and reductionist perspective - as some of my own colleagues would no doubt argue-a cognitive approach in fact offers us a way out of our disciplinary dilemma. It need not supplant postmodernist or any other theory or methodology; what it can do, rather, is to help us place those theories or methodologies in a larger and potentially more useful context.

The chief advantage of a cognitive approach is that it takes into account the way in which the mind actually works. There is nothing new in setting such a goal, of course: psychoanalytic criticism-from Freud himself to Norman Holland to Lacan-proposes to do the same thing, and it can be argued that reader response criticism would be meaningless without the assumption that we can actually deconstruct the process of reading and interpreting a text. But both psychoanalytical and reader response criticism are culture-bound; that is, psychoanalytical theory-whose lack of empirical basis is now a commonplace among all except Freud's hardest-core disciples-is itself inescapably the product of a particular place and time, and reader response criticism, especially in Stanley Fish's concern with interpretive communities, is often as concerned with cultural discourses as with cognitive processes. What an integrated cognitive approach can do is to try to distinguish those cognitive processes from cultural and other epiphenomena, in order to deal in some useful fashion with the way in which the human mind makes meaning out of texts.

A case in point is the postmodern assertion of the indeterminacy of meaning: the insistence on undecidability as an inevitable consequence of the infinite deferral of meaning, and on aporia as universal evidence of textual self-subversion. The problem, it seems to me, is that in practical terms such an assertion runs counter to the way in which real readers 
read real texts. As a number of writers have pointed out-assuming, of course, that we can trust their texts not to self-deconstruct-the normal condition of human beings, readers and writers included, is an insistence on determinate meaning. It is the absence of such an insistence that is worthy of comment.

What is especially interesting is that over the course of the nineteenth and twentieth centuries, writers have construed cognitive dualism in both positive and negative terms, but always as a deviation from a presumed norm. In Nineteen Eighty-Four, for example, Orwell imagined doublethink-like Newspeak - as the product of social engineering, designed to produce subjects (or objects) unnaturally capable of thinking two contradictory thoughts at once. John Keats saw such an ability as a special talent rather than as a product of totalitarian coercion, but he considered it equally abnormal: in trying to identify what sets a "man of achievement" like Shakespeare apart from other men, he defined "Negative Capability" as "when a man is capable of being in uncertainties, mysteries, doubts, without any irritable reaching after fact or reason" (528). F. Scott Fitzgerald, examining the sources and symptoms of his own breakdown, declared in "The Crack-Up" that "the test of a first-rate intelligence is the ability to hold two opposed ideas in the mind at the same time, and still retain the ability to function" (69). And, not surprisingly, Lewis Carroll weighed in on the subject in Through the Looking-Glass, in an exchange between the matter-of-fact Alice and the White Queen:

Alice laughed. 'There's no use trying,' she said: 'one can't believe impossible things.'

'I daresay you haven't had much practice,' said the Queen. 'When I was your age, I always did it for half-an-hour a day. Why, sometimes I've believed as many as six impossible things before breakfast.' (153)

If such an ability is reserved for totalitarian subjects, Shakespeares, extraordinary minds, and strange characters in little girls' dreams, then the rest of us presumably find it difficult or impossible to make more than one meaning at a time; and the chief constraint on that meaning is likely to be our sense of empirical reality. (Think, for example, of Samuel Johnson kicking the stone and announcing, "Thus I refute Berkeley.") That is consistent with the findings of cognitive science-one of whose goals is to identify and map the ways in which we process external information-and with the hypotheses of evolutionary psychology, which Steven Pinker describes as

bring[ing] together two scientific revolutions. One is the cognitive revolution of the 1950 s and 1960s, which explains the mechanics of thought and emotion in terms of information and computation. The other is the revolution in evolutionary biology of the 1960s and 1970s, which explains the complex adaptive design of living things in terms of selection among replicators. The two ideas make a powerful combination. Cognitive science helps us to understand how a mind is possible and what kind of mind we have. Evolutionary biology helps us to understand why we have the kind of mind we have. (How the Mind Works 23)

One of the tenets of evolutionary psychology is that "mind" is not a single entity, but rather a series of interconnected modules designed to perform different specific functions; The Language Instinct, for example, is Pinker's explanation of the module that enables and controls our use of language. (A recent article in The New York Times reports that a simi- 
larly innate impulse to design and build has been proposed by an art historian in a study titled The Monumental Impulse: Architecture's Biological Roots [Boxer].) Another tenet is that these modules have evolved by a process of natural selection, and are therefore designed to improve our chances of survival in a Darwinian universe-though modules that evolved millennia ago on the plains of East Africa may in some cases serve us poorly in an urban society on the cusp of the twenty-first century. It is these modules that, each in its own way, make it possible for us to deal systematically (and successfully) with the world around us.

It is not necessary, however, to subscribe to all of evolutionary psychology in order to posit the existence of some part of the mind that can be characterized as inferential or inductive, some module (or combination of modules) that enables us to make meaning out of an often chaotic environment. Imagine, for example, Og the caveman trying to decide whether that saber-tooth tiger crouching on the rock is real or not, or whether there is anything to fear in the growling that he hears just outside the cave mouth: for him not to assume the determinate reality of what his senses tell him would be not only counter-intuitive but also, to say the least, maladaptive. If Johnson's stone had been a boulder falling off a cliff, I suspect that even Berkeley would have gotten out of the way.

And if this is so, it also seems to me both counter-intuitive and unnatural to assert the indeterminacy of meaning as a first principle of textual analysis. The human mind is a meaning-making machine; if it were not, we would be a footnote to some other species's history of evolution by now. All criticism of the fallacies of logocentrism notwithstanding, we make meaning-or try to make meaning-out of language in the same way that we make meaning - or try to make meaning — out of everything else. To assert that meaning is unstable because language ultimately refers only to other language is to ignore a key reason that language exists in the first place: to allow us to refer to particular things and to communicate particular ideas. If Caveman Og's companions are in no doubt about his meaning when he shouts, "Watch out for the saber-tooth tiger!" neither should we doubt that what ordinary readers do with a written text is to make meaning out of it. They may get it wrong (from our perspective, or from the author's), or disagree among themselves about what that meaning may be, but they assume that there is a meaning there and that their job as readers is to find it. Those of us who consider ourselves more sophisticated readers should not forget that. The insights of reader-response criticism may help us to explain how different readers make different meanings out of the same text-but only if we ground our metareading in an awareness that, for the individual reader, meaning is not provisional or indeterminate or infinitely deferred, By situating us in an evolutionary rather than a purely cultural context, cognitive science reminds us that making such meanings is what we do as human beings. Linguists have long since discovered that the study of language necessarily entails an understanding of how the human mind works; as literary and cultural critics we should not insist on trying to legislate that mind out of existence.

If a cognitive approach, then, insists on paying careful attention to the human mind as a meaning-making organ, it can also enable us to deal more usefully with the concept of "culture," by distinguishing between cognitive universals and cultural epiphenomena. 
When my unhappy undergraduate complained about my linguistics course, for example, one source of her dissatisfaction was the refusal to take culture sufficiently into account as a factor in language acquisition:

. . . sure, Pinker says that as long as a child is exposed to a language, the child can acquire the language. But are there any other factors relevant to the process of language acquisition? What about cultural differences between children? By not including cultural influences [in] his argument, I am assuming that they carry no weight.

The fact of the matter, of course, is that they do carry no weight; as Pinker had pointed out in his book, and as I had pointed out in class, children acquire language at the same rate, and make the same sorts of "mistakes" at the same age, in all cultures and all language communities. Language acquisition is instinctive, biologically determined, beyond anyone's conscious control; culture has nothing to do with it.

What happened is that, as a well-trained postmodernist, my student insisted on a role for "culture" in everything, when in fact, as Chomsky and his followers have long since demonstrated, the basic structure of human language is universal across all cultures. For example, the Sapir-Whorf Hypothesis - that our perception of reality is determined by the particular structures of our native language- has been seriously undermined by post-Chomsky research into linguistic universals. And if scientists appeal to empiricism to challenge the notion of epistemic relativism in the physical and natural sciences, any totalizing appeal to such relativism in the social sciences and humanities-e.g. in the notion of cultural discourse-must be called into question by a theory of cognitive universals. In How the Mind Works, Pinker attacks the Standard Social Science Model that treats culture as "an autonomous entity that carries out a desire to perpetuate itself by setting up expectations and assigning roles, which can vary arbitrarily from society to society" (45); in The Language Instinct he cites the work of an anthropologist who, on the basis of a survey of diverse cultures, has proposed a "Universal People" model based on cultural universals, and then offers his own provisional list of the mental modules that might help to explain those universals $(413-15,420)$. There is evidence that such modules and such universals do in fact exist, e.g. in cross-cultural similarities among all known ethnobotanical taxonomies and our own Linnaean system of classification (Pinker, The Language Instinct 422-23); if they do, then we need at least to qualify our reliance on culture and cultural discourse as shapers of human behavior in general and of texts in particular.

At this point, let me emphasize that when I propose that we qualify our reliance on culture and cultural discourse, or that we reconsider our insistence on the indeterminacy of meaning, I am not arguing that we adopt a monolithically "cognitive" approach as opposed to a monolithically "postmodernist" approach to literary studies. (As postmodernism tells us, nothing is genuinely monolithic anyway.) I am not arguing, for example, that we abandon Derrida's postulation of différance and of the indeterminacy of meaning. Nor do I deny that it is a seductive problem: when I was in my first year of high school, almost forty years ago, I played a game with my best friend in which I would ask him to define a word, then ask him to define a word in his definition, then ask him to define a word in the second definition, and so on, until we got tired. 
What I do ask, however, is that we leave such problems to the philosophers, or recognize that when we take them up we are outside the realm of textual criticism-just as the philosopher and art critic Arthur Danto observes that the rise of conceptual art in the sixties "meant that as far as appearances were concerned, anything could be a work of art, and it meant that if you were going to find out what art was, you had to turn from sense experience to thought. You had, in brief, to turn to philosophy" (13). Some problems are interesting without being solvable-or, more to the point, applicable in any practical sense to literary (or other) texts. In the Middle Ages the question of how many angels could dance on the head of a pin was an important problem to theologians, but of little practical consequence to faithful Christians to whom the possibility that angels might not have a material existence made them no less real.

In How the Mind Works Pinker argues that one consequence of the mind's evolution as a meaning-making organ is the fact that some problems are simply beyond our innate meaning-making faculty:

The intellect evolved to crack the defenses of things in the natural and social world. It is made up of modules for reasoning about how objects, artifacts, living things, animals, and other human minds work .... There are problems in the universe other than those: where the universe came from, how physical flesh can give rise to sentient minds, why bad things happen to good people, what happens to our thoughts and feelings when we die. The mind can pose such questions but may not be equipped to answer them, even if the questions have answers. Given that the mind is a product of natural selection, it should not have a miraculous ability to commune with all truths; it should have a mere ability to solve problems that are sufficiently similar to the mundane survival challenges of our ancestors. According to a saying, if you give a boy a hammer, the whole world becomes a nail. If you give a species an elementary grasp of mechanics, biology, and psychology, the whole world becomes a machine, a jungle, and a society. I will suggest that religion and philosophy are in part the application of mental tools to problems they were not designed to solve. (525)

The corporality of angels is certainly such a problem; but so, it seems to me, is the indeterminacy of meaning. Let me go one step further: meaning itself is such a problem: what do we mean when we talk about meaning? Even linguists have a harder time getting a handle on semantics than on any other part of a grammar. But if we propose to talk about meaning - and that is what most of us do, even when we insist that meaning is socially constructed - then we need to assume that our minds are programmed to find such a thing, in texts as in the world around us. Philosophers may put scare quotes around "meaning," but readers don't, and literary critics shouldn't, even when they disagree about what the nature of meaning is.

What, then, might a cognitive approach to literary study look like? That's certainly an open question; the Modern Language Association, in fact, has established a discussion group in Cognitive Approaches to Literature. The category is plural: the idea of a single cognitive approach to literary studies makes no more sense than the idea of a single postmodern or postmodernist approach. What cognitive approaches are all likely to have in common, of course, is a receptivity to the insights of cognitive science, and thus an awareness that texts are ultimately (a) products of mind and (b) artifacts of linguistic communi- 
cation-an awareness that can free us to ask certain types of questions about texts and textuality, and limit the usefulness of others. The basic principle of such an approach would be that written texts, literary and otherwise, are determined, at least in part, by fixed structures in the human mind: in Pinker's terms, modules (or networks of modules) that, in addition to making meaning, predispose us to particular ways of thinking and communicating. This principle would enable us to ground our discussion of literary (and other texts) in a coherent theory of mind: in other words, to qualify any notion of "free play" by acknowledging the ways in which the production and interpretation of texts are governed by universal constraints. Such constraints, it seems to me, must condition the ways in which we deal with language (literary and otherwise) and with such "literary" devices as metaphor and narrative structure.

At the simplest level, for example, any study of linguistic experimentation should take into account the constraints of universal grammar, which have been well documented by linguists. A text like Finnegans Wake may in fact be "difficult" not simply because it violates our expectations about literary texts or texts in English, but because it violates universal rules governing language use; in other words, our linguistic competence-our language module-is incapable of making sense out of it without help from other cognitive faculties. On the other hand, an experimental poem like e e cumming's "anyone lived in a pretty how town" is more accessible because its violations of grammar are more limited, and the meaning of anomalous forms is largely recoverable through linguistic competence alone. And Lewis Carroll's "Jabberwocky," though not meaningful in any conventional sense-as Alice says, "Somehow it seems to fill my head with ideas-only I don't know exactly what they are!" (118)-is nevertheless easily understandable as a linguistic text, even without Humpty Dumpty's gloss. (I routinely use "Jabberwocky" in my linguistics classes to demonstrate to my students that they can place words in grammatical categories without having the faintest idea of what those words mean.)

William Dowling has applied a cognitive approach to the language of more conventional literary texts in his recent book The Senses of the Text, in which he uses a theory of intensional semantics, and Chomskyan linguistics in general, to argue against the indeterminacy of meaning: "The entire value of [Jerrold] Katz's New Intensionalism is that it demonstrates the sense in which the linguistic system carries within itself . . the means to determine that a word or a phrase means one thing rather than another, $\mathrm{X}$ rather than $\mathrm{Y}$. Then ... one is also given a means of understanding the ways in which errors at the level of primary meaning inevitably produce errors in second-order interpretation" (88). He argues, for example, that failure to pay proper attention to specific words in Donne's "Valediction: Forbidding Mourning" and Elegy XIX ("To His Mistress Going to Bed") can give rise to facile but inappropriate readings of texts with determinate seventeenth-century meanings

As for those more "complex" elements, like metaphor and narrative structure, that we think of as constituting the "literary" features of literary texts, they can be accounted for in cognitive terms as well. In Reading Minds, for example, Mark Turner explores the ways in which John Ashbery's poem "At North Farm" recapitulates the journey motif that it shares 
with Pilgrim's Progress and the Gospel according to John, and suggests that the structural similarity is neither conscious nor accidental:

It is predictable and unobjectionable that literary criticism would attend in the main to those aspects of imagination that might be expected to vary from age to age, or country to country, or author to author, or even passage to passage. We are vigilant for the new and the variable. But attending to what varies and not to what abides means that we see only a contingent aspect, when we believe ourselves to be seeing the whole. [Pinker makes the same observation about anthropologists in The Language Instinct (411-13).] In one respect, to understand the sophisticated ways in which the Ashbery poem can work we must understand the unoriginal structure of invention it shares with both Pilgrim's Progress and the Farewell Discourse from the Fourth Gospel. To understand its originality is in one respect to understand its movement to satisfy an abiding unoriginal constraint on metaphor that Pilgrim's Progress satisfies in a prefabricated way and the Farewell Discourse satisfies in its own original way: a constraint that governs, guides, and empowers all these poems. It is not possible to analyze an arresting and novel poem such as "At North Farm" without considering those unoriginal structures of invention that are the known space in which imagination moves, and whose constrained exploitations is poetic originality. (64-65)

Almost twenty years ago, in Metaphors We Live By, George Lakoff and Mark Johnson argued that metaphor revealed the workings of mind: that linguistic metaphor - the metaphoric structure of ordinary language, as opposed to the special case of literary metaphorwas a window into the way we think. Lakoff later elaborated on that cognitive approach to language in Women, Fire, and Dangerous Things: What Categories Reveal about the Mind. What Turner is doing now, and has been doing for some time, is to argue that, since literature manifests itself as language, any cognitive theory of language must necessarily imply a cognitive theory of literature as well.

Nor is metaphor the only aspect of literary language or structure that is susceptible to cognitive analysis. Psychologists and narratologists, for example, have identified narrative as a universal structuring device; it has even been suggested that we remember things by embedding them in narratives (and that our earliest childhood memories go back only to the point at which we became capable of ordering events into narratives). If that is so-if one or more of our mental modules are programmed to generate and appreciate (and expect) narrative structures of certain kinds - then that fact is relevant to our response to narrative fictions, and to the ways in which we can usefully think about those fictions. Just as the experimental language of a novel like Finnegans Wake may resist our attempts to make meaning of it for cognitive and not merely cultural reasons, the experimental plot structures of postmodern fictions may be "difficult" simply because they make demands on us beyond the capacities of our innate algorithms for narrative: the non-linear structures of hyperfiction, for example, or the fragmented narratives and multiple realities of stories like Robert Coover's "The Babysitter" and "The Elevator." In The Crying of Lot 49, in which Thomas Pynchon thumbs his nose at our quest for determinate meaning, is it possible that readers' frustration with the ending-in which Pynchon cuts his novel off just as the central plot question is about to be resolved-is the result not just of cultural and educational conditioning, but of some thwarted instinctive desire for narrative closure? 
I am not sure yet about how to integrate a cognitive approach into the courses that I teach, beyond raising the kinds of questions and issues that I have tried to raise here. Using metaphor as a bridge between language and literature and between culture and cognition is one possibility. James E. Seitz has recently proposed just such a strategy in Motives for Metaphor: Literacy, Curriculum Reform, and the Teaching of English, and even textbook publishers are getting into the act: the brochure advertising a new anthology of essays for first-year writing courses, Figures of Thought for College Writers, describes it as "an innovative reader informed by the idea that metaphor is basic to our cognitive processes and one of our principal ways of structuring and understanding concepts." Another possibility is to encourage individual students' research into the intersection of cognitive science with literary studies; a student of mine, for example, is preparing to write her master's thesis on the application of Howard Gardner's cognitive model of creativity to literary texts. More immediately, in response to students's questions about the relevance of linguistics to their literary studies-and to postmodernist colleagues' skepticism about the place of linguistics in our graduate curriculum-I have incorporated Mark Turner's The Literary Mind into my graduate linguistics syllabus. The subtitle of his book is The Origins of Thought and Language, and I hope that it will encourage my students to investigate the relationship between cognitive and literary studies and between language and literature. As Turner sums up his own argument,

[w] ith story, projection, and their powerful combination in parable, we have a cognitive basis from which language can originate. The dynamic processes of parable are basic to the construction of meaning and the construction of language. Story precedes grammar. Projection precedes grammar. Parable precedes grammar. Language follows from these mental capacities as a consequence; it is their complex product. Language is the child of the literary mind. (168)

I do not plan to argue to my students that cognitive science is as central to literary analysis as it is to the study of language. There are too many aspects of literature that cannot yet be accounted for by cognitive theory. Some of them, I suspect, will never be susceptible to such analysis. But I do believe that a cognitive approach affords us an opportunity to resolve some of the antagonisms that divide our discipline and the academy in general: linguists vs. literary critics, humanists vs. scientists, postmodernists vs. pre- and antipostmodernists. Linguists are fond of pointing out that nearly every sentence that we utter is brand-new in the history of the human species, but they also point out that our creative potential exists only within a context of innate linguistic constraints. If similar enabling constraints exist on our literary creativity, as Turner and other cognitivists suggest that they do, then categories like "author," "text," and "cultural discourse" cannot be usefully considered without taking those constraints into account. And since a good deal of such a cognitive approach would be based on empirical research-that is, on theory in its scientific sense-the gap of incomprehension and hostility that has opened between the humanities and the natural sciences might be at least partially closed.

I have too much respect for Thomas Kuhn and the history of science to assert a paradigm shift in literary studies, and too much respect for much of postmodernist theory to claim that it has been rendered entirely obsolete by cognitive theory. (The head of my de- 
partment has offered the opinion that cognitive theory is the next cutting edge in literary studies; some of my postmodernist colleagues have occasionally considered me a troglodyte, but I prefer not to return the favor.) Even the sociobiologist Edward O. Wilson, in his own attempt at a unified-field theory of knowledge, acknowledges reluctantly that practitioners of postmodernist antirationalism have a place in his system:

As today's celebrants of corybantic Romanticism, they enrich culture. They say to the rest of us: maybe, just maybe, you are wrong. Their ideas are like sparks from firework explosions that travel away in all directions, devoid of following energy, soon to wink out in the dimensionless dark. Yet a few will endure long enough to cast light on unexpected subjects. (47)

What I do believe, however, is that the application of cognitive research to literary studies has the potential to curb some of the theoretical excesses and pedagogical malpractices of academic postmodernism, and that by doing so it can help us bridge some of the ideological divides that Edward Said lamented in his MLA President's Column. An integrated cognitive approach can provide coherence to English studies and help restore order and balance to the relationship between literary studies and the rest of the academy. If there is a middle ground in the Culture Wars-if there is a better way to define our discipline-it seems to me that this may be it.

\section{WORKS CITED}

Boxer, Sarah. "Blueprints in Genes: Architect's Body of Work May Be More Than Just Metaphor." The New York Times on the Web October 2, 1999. <http://www.nytimes.com/yr/mo/day/news/art/anatomy-architecture.html>

Danto, Arthur C. After the End of Art: Contemporary Art and the Pale of History. Princeton: PUP, 1997.

Eagleton, Terry. The Illusions of Postmodernism. Oxford: Blackwell, 1996.

Carroll, Lewis [Charles Lutwidge Dodgson]. Through the Looking-Glass. Alice in Wonderland: Authoritative Texts of Alice's Adventures in Wonderland, Through the Looking-Glass, The Hunting of the Snark; Backgrounds; Essays in Criticism. Ed. Donald J. Gray. New York: Norton, 1971. 101-209.

Childers, Joseph and Gary Hentzi. The Columbia Dictionary of Modern Literary and Cultural Criticism. New York: Columbia UP, 1995.

Dowling, William. The Senses of the Text: Intensional Semantics and Literary Theory. Lincoln: U of Nebraska P, 1999.

Elbow, Peter. What Is English? New York: Modern Language Association; Urbana: National Council of Teachers of English, 1990.

Figures of Thought for College Writers, ed. Dona J. Hickey. Publisher's brochure. Mountain View, CA: Mayfield, 1999. 
Fitzgerald, F. Scott. "The Crack-Up." The Crack-Up. Ed. Edmund Wilson. New York: New Directions, 1945. 69-74.

Gross, Paul R., Norman Levitt, and Martin W. Lewis, eds. The Flight from Science and Reason. New York: New York Academy of Science, 1996.

Keats, John. "To George and Thomas Keats." December 28, 1817. Letter 26 [30] in Complete Poems and Selected Letters. Ed. Clarence De Witt Thorpe. New York: Odyssey, 1935. 527-28.

Kuhn, Thomas S. The Structure of Scientific Revolutions. 2nd ed. Chicago: U of Chicago P, 1970.

Lakoff, George. Women, Fire, and Dangerous Things: What Categories Reveal about the Mind. Chicago: U of Chicago P, 1987.

Lakoff, George and Mark Johnson. Metaphors We Live By. Chicago: U of Chicago P, 1980.

Norris, Christopher. What's Wrong with Postmodernism: Critical Theory and the Ends of Philosophy. Baltimore: Johns Hopkins UP, 1990.

Orwell, George [Eric Blair]. Nineteen Eighty-Four. 1949. New York: Signet-New American Library, 1961.

Pinker, Steven. How the Mind Works. New York: Norton, 1997.

- The Language Instinct: How the Mind Creates Language. New York: Morrow, 1993.

Poovey, Mary. "Beyond the Current Impasse in Literary Studies." Rev. Of What's Happened to the Humanities? Ed. Alvin Kernan. American Literary History 11 (1999): 35477.

Said, Edward. "President's Column: Restoring Intellectual Coherence." MLA Newsletter Summer 1999: 3-4.

Schilb, John. Rev. of Language and Limits: Resisting Reform in English Studies, by Myron C. Tuman. South Atlantic Review 64 (1999): 168-70.

Seitz, James E. Motives for Metaphor: Literacy, Curriculm Reform, and the Teaching of English. Pittsburgh: U of Pittsburgh P, 1999.

Sokal, Alan. "Transgressing the Boundaries: Toward a Transformative Hermeneutics of Quantum Gravity." Social Text $46 / 47$ (1996): 217-52.

Sokal, Alan and Jean Bricmont. Fashionable Nonsense: Postmodern Intellectuals' Abuse of Science. New York: Picador USA, 1998.

Turner, Mark. The Literary Mind: The Origins of Thought and Language. NewYork: Oxford UP, 1996. 
- Reading Minds: Studying English in an Age of Cognitive Science. Princeton: PUP, 1991.

Wellek, René and Austin Warren. Theory of Literature. 1942. Rev. ed. New York: HarvestHarcourt, Brace, 1956.

Wilson, Edward O. Consilience: The Unity of Knowledge. 1998. New York: VintageRandom House, 1999. 
